\title{
The Mental Capacity Act and mental healthcare in prison: opportunities and challenges ${ }^{\dagger}$
}

\author{
Sharon Davies, ${ }^{1}$ Claire Dimond ${ }^{2}$
}

The Psychiatrist (2012), 36, 241-243, doi: 10.1192/pb.bp.111.036988

${ }^{1} \mathrm{HM}$ Prison and Young Offender Institution Feltham, UK; ${ }^{2}$ West London Mental Health NHS Trust, UK

Correspondence to Sharon Davies (sharon.davies@wlmht.nhs.uk)

First received 21 Sep 2011, final revision 25 Jan 2012, accepted 14 Feb 2012
Summary The UK Mental Health Act 1983 does not apply in prison. The legal framework for the care and treatment of people with mental illness in prison is provided by the Mental Capacity Act 2005. We raise dilemmas about its use. We highlight how assessing best interests and defining harm involves making challenging judgements. How best interests and harm are interpreted has a potentially significant impact on clinical practice within a prison context.

Declaration of interest None.
The Mental Capacity Act 2005 provides a framework for making health and social care decisions for people who lack capacity to make a decision about their own care. It applies to all people aged 16 years and over in England and Wales, including those in prison, and provides a legal framework to rationalise the care of mentally ill people in prison. The Mental Health Act 1983 does not apply in prison or other parts of the secure custodial estate, therefore until the introduction of the Mental Capacity Act people with mental illness in prison who refused treatment and lacked capacity to make treatment decisions have had treatment decisions taken under the 'common law' rubric. Sections 5 and 6 of the Mental Capacity Act provide a general defence to acts of care and treatment, which may involve restraint of a person who lacks capacity, codifying the common law. Section 5 ('Acts in connection with care and treatment') provides protection from liability for whoever performs an act in relation to care and treatment, so long as they reasonably believe that the person lacks capacity in relation to the act, and the act is in their best interests. Section 6 ('Section 5 acts: limitations') specifies that whoever performs an act involving restraint must reasonably believe that the act is both necessary to prevent harm and proportionate to the likelihood and seriousness of the harm.

The rates of serious mental illness including psychosis in prisoners are several times higher than in the general population, so the potential scope of application of the Mental Capacity Act in prison healthcare is significant. ${ }^{1}$ Prisoners with mental illness have tended to be treated against their will infrequently and only in emergency situations. $^{2}$ Transfer of prisoners who are unwell is frequently delayed and thus initiation of treatment can be delayed, with the result that prisoners receive care not in keeping with current best evidence or good practice guidelines. ${ }^{3}$ Before the introduction of the Mental Capacity

'See commentary, pp. 243-244, this issue.
Act there were arguments for the development of policy in line with the view that case law allowed for more extensive treatment of mentally incapacitous prisoners than just that given in emergency situations. ${ }^{4}$ It is acknowledged that there are potential risks in this approach, as good response to treatment in prison may mean that conditions for transfer to hospital are no longer met, depriving mentally ill prisoners of a more appropriate standard of care.

In tandem with psychiatrists' concerns over lack of adequate treatment of prisoners with mental illness, case law concerning Article 3 of the European Convention on Human Rights (as enacted in the UK by the Human Rights Act 1998) has evolved to include situations involving prison healthcare. ${ }^{5}$ Article 3 is the only absolute right and states that 'No one shall be subjected to torture or to inhuman or degrading treatment or punishment.' Article 3 case law has extended beyond concern about the commission of acts to include 'omissions' such as the absence of appropriate medical treatment. This could potentially include omissions of treatment for mentally ill prisoners who do not meet the threshold for emergency treatment. ${ }^{6}$

Psychiatrists in England and Wales have been slow to recognise the need to take the Mental Capacity Act into account in the treatment of psychiatric in-patients, particularly when making judgements about best interests. ${ }^{7}$ Similarly, a recent study on prison healthcare wings refers to emergency treatment under common law rather than the Mental Capacity Act. $^{8}$ We raise a number of dilemmas regarding implementation of the Act within prison in relation to people with psychotic illnesses.

\section{Prison Service Orders and the Mental Capacity Act}

Prison Service Order (PSO) 1600 - Use of Force, is the framework under which 'use of force' by prison staff is considered 'lawful'; it was issued in 1999, with amendments in 2003. Although prisons are not excluded from the scope 
of the Mental Capacity Act (see the Code of Practice, Section 10.73), ${ }^{9}$ PSO 1600 states that it is underpinned by the Criminal Law Act 1967 Section 3(1); Prison Rule 47/Young Offender Institution Rule 50; the Human Rights Act 1998 (in particular Articles 2, 3 and 8) and common law. No reference is made to the Mental Capacity Act. Reconciling the Act with PSO 1600 is potentially problematic. Prison Service Order 1600 outlines the use of force as justified and lawful only where it is reasonable in the circumstances, it is necessary, no more force than is necessary is used, and it is proportionate to the seriousness of the circumstances. To determine whether the action is necessary to prevent harm, the following risks are suggested: risk to life, limb, property and the risk to the 'good order of the establishment' (PSO 1600 Section 1.1: 'Theory and Law surrounding the use of force'). Circumstances where mental health professionals may consider the use of force to be justified in the 'best interests' of a person's health and social care may not be covered by PSO 1600, leading to the potential conflicts between healthcare and prison staff. Examples in our experience include use of restraint, when all other interventions have not been successful, to transfer to healthcare a resisting prisoner who is very unwell with a psychotic illness; or to provide basic nursing care for a prisoner with a psychotic illness as a consequence of which they have refused to wash for many weeks.

\section{Best interests}

Assessing and acting in the best interests of prisoners with mental illness is complex. The best interests checklist in the Mental Capacity Act Code of Practice (Chapter 5) ${ }^{9}$ recommends that 'views of other relevant people' be sought and taken into account when identifying best interests in treatment decisions for people who lack capacity. Many young people and adults within prison have complicated relationships with family members and are frequently estranged from them. Personal relationships with partners or family can often be fraught and potentially the victims of the offences for which they are in custody. Studies consistently indicate that a significant number of young people in the secure custodial state have been looked after by Social Services. ${ }^{10}$ Young people who are 'looked after' are commonly de-accommodated on reception into custody, and even if still formally 'looked after' do not have assigned professionals who have established relationships with them and might have informed ideas of their pre-morbid best interests. Prisoners who are unwell may be reluctant to give consent to professionals to contact their family or friends, particularly just after their remand. In the context in which we work, a significant percentage of the prison population are foreign nationals with limited social contacts in the UK.

The use of independent mental capacity advocates (IMCAs) is recommended in the Mental Capacity Act Code of Practice in situations where there is difficulty ascertaining best interests in decisions about serious medical treatment. Serious medical treatment is not defined in the Act, but we question whether given the context of prison healthcare the IMCA should be consulted at a lower threshold.
In our own practice we have introduced a 'best interest case conference' including prison officers and representatives from the prison 'Safeguards' department, Independent Monitoring Board, and, where relevant, primary healthcare to assist in thinking about best interests in circumstances where a mentally ill incapacitous prisoner is refusing care or treatment and restraint is being considered. This involved providing training to prison and healthcare staff and establishing a joint protocol. We have not yet been able to include IMCAs in these meetings.

\section{Defining harm}

The concept of harm, its seriousness and likelihood, is central to the justification for the use of restraint involved in acts of care and treatment. How does one define harm in the prison context?

An obvious harm is physical harm that could result when a prisoner has an untreated psychotic illness and as a consequence of agitation, confusion or paranoia they assault someone, and then are restrained in an emergency situation or are themselves assaulted by others in retaliation or because of their behaviour. Not infrequently, paranoid psychosis results in the person not eating or drinking sufficiently due to persecutory beliefs regarding food or water being contaminated, leading them to self-harm.

Psychological or emotional harm can also be significant, although it is less clear-cut in terms of decision-making under the Mental Capacity Act. In the prison context, a person who is very unwell and extremely agitated and threatening will often be on a restricted regime, which may mean they come out of their cell for brief periods of time, often a maximum of 1 hour a day. As a result, a lot of time is spent isolated in their cell, with potential further deterioration in mental state. Suicidality and self-harm in the context of mental illness may be another significant harm to consider.

Delaying treatment while awaiting hospital transfer can result in a deteriorating mental state and be associated with increasing risk to others, such that on transfer a higher level of security is needed than would have been the case if treatment with an antipsychotic were commenced at an earlier stage of illness. In general, the evidence suggests that delaying treatment in first-episode psychosis is associated with worse outcomes. ${ }^{11}$

In a prisoner with a definitive diagnosis of psychotic illness and a history of non-adherence to treatment, administering a depot medication when the prisoner is incapacitated and refuses treatment could be argued to meet both best interests and the harm conditions better than one emergency dose of intramuscular medication, which would be likely to require repeated treatment and concomitant further restraint.

\section{About the authors}

Sharon Davies is consultant adolescent forensic psychiatrist at HM Prison and Young Offender Institution Feltham and The Wells Unit (a secure adolescent forensic unit). Claire Dimond is consultant adolescent forensic psychiatrist and clinical lead for the Adolescent Forensic Directorate, West London Mental Health NHS Trust. 


\section{References}

1 Fazel S, Danesh J. Serious mental disorders in 23000 prisoners: a systematic review of 62 surveys. Lancet 2002; 359: 545-50.

2 Wilson S, Forrester A. Too little too late? The treatment of mentally incapacitated prisoners. J Forensic Psychiatry 2002; 13: 1-8.

3 McKenzie N, Sales B. New procedures to cut delays in transfer of mentally ill prisoners to hospital. Psychiatr Bull 2008; 32: 20-2.

4 Earthrowl M, O'Grady J, Birmingham L. Providing treatment to prisoners with mental disorders: development of a policy. Selective literature review and expert consultation exercise. $\mathrm{Br} J$ Psychiatry 2003; 182 299-302.

5 Curtice M, Sandford J. Article 3 of the Human Rights Act 1998 and the treatment of prisoners. Adv Psychiatr Treat 2010; 16: 105-14.

6 Curtice M. The European Convention on Human Rights: an update on Article 3 case law. Adv Psychiatr Treat 2010; 16: 199-206.
7 Owen GS, Szmukler G, Richardson G, David AS, Hayward P, Rucker J et al. Mental capacity and psychiatric in-patients: implications for the new mental health law in England and Wales. Br J Psychiatry 2009; 195: 257-63.

8 Forrester A, Chua K, Dove, S, Parrott J. Prison health-care wings: psychiatry's forgotten frontier? Crim Behav Ment Health 2010; 20: 51-61.

9 Department for Constitutional Affairs. Mental Capacity Act 2005 Code of Practice. TSO (The Stationery Office), 2007.

$10 \mathrm{HM}$ Inspectorate of Prisons. Thematic Report by HM Inspectorate of Prisons: The Care of Looked After Children in Custody. A Short Thematic Review. HMIP, May 2011

11 Marshall $M$, Lewis $S$, Lockwood $A$, Drake $R$, Jones $P$, Croudace $T$. Association between duration of untreated psychosis and outcome in cohorts of first-episode patients: a systematic review. Arch Gen Psychiatry 2005; 62: 975-83.

\title{
Compulsory treatment in prison
}

\section{Commentary on ... The Mental Capacity Act and mental healthcare in prison ${ }^{\dagger}$}

\author{
Simon Wilson ${ }^{1}$
}

The Psychiatrist (2012), 36, 243-244, doi: 10.1192/pb.bp.112.039511

${ }^{1}$ Institute of Psychiatry, London, UK Correspondence to Simon Wilson (simon.wilson@kcl.ac.uk)

First received 2 Apr 2012, accepted 2 April 2012
Summary It is generally stated that the Mental Health Act 1983 does not apply to prisoners, and this is a useful shorthand to remind those unfamiliar with British prisons that treatment cannot be administered under the Mental Health Act, even to the most severely mentally ill prisoners. However, the legal situation is actually more nuanced given that the Mental Health Act does make provision for prisoners intending that they be promptly transferred to hospital for treatment. This does not happen in practice for service reasons. It is not clear whether the Mental Capacity Act 2005 applies to those falling through the cracks.

Declaration of interest None.
It is often said that the Mental Health Act 1983 does not apply to prisoners in England and Wales, but that is not strictly true. It is a useful shorthand to remind those new to prison health services that a prison healthcare unit is not a hospital, and that despite containing some of the most severely mentally ill people one is ever likely to see as a psychiatrist in this country, those individuals are not detained for treatment under the Mental Health Act.

Davies \& Dimond ${ }^{1}$ remind us that the Mental Capacity Act 2005 has some applicability in the prison situation, but that using it effectively requires us to be better clinicians thinking about 'best interests' broadly, consulting those who

"See editorial, pp. 241-243, this issue. know the prisoner well, and weighing up harms and benefits. This is to be welcomed and is an improvement on the common law that preceded it. The authors also, helpfully, remind us how difficult it is for HM Prison Service as an organisation to think about health issues when drawing up documents such as Prison Service Order (PSO) 1600.

The Mental Capacity Act, of course, applies to providing treatment for adults who lack capacity to make treatment decisions and for whom that treatment is in their best interests. It was primarily intended for the treatment of physical disorders, and in those with intellectual impairments and dementia. There will be a group of prisoners, like all other people, to whom this applies. The Act, however, was not intended for the severely mentally ill 